\title{
The confidence to deliver
}

EQUIA Forte is the latest innovative bulk fill glass hybrid restorative system from GC which the company says is fast becoming the first-choice alternative to amalgam.

A combination of glass ionomer and resin technologies, EQUIA Forte combines
EQUIA Forte Fil and EQUIA Forte Coat.

United, they build a stronger, superior posterior bulk fill material suitable for all age groups.

Dr Akit Patel, Specialist in Prosthodontics, said: 'EQUIA Forte is my key material for cores, dentine substitute and as a final

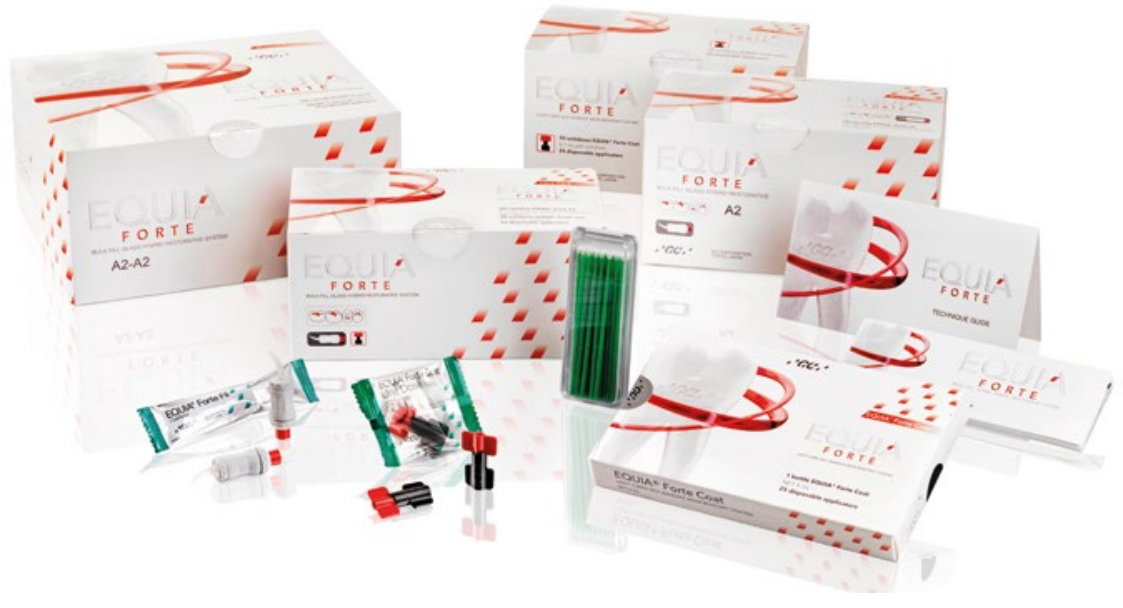

restoration for many posterior cavity configurations. It is easy to handle, use, adapt and sculpt, making placement faster with great results. Its high strength, coupled with its ability to chemically bond to tooth structures, gives me the confidence and predictability in providing successful direct restorations.'

Stronger, faster, easy to handle and with impressive aesthetics, EQUIA Forte widens a dental professional's posterior restorative options, enabling them to meet or beat all of their patients' expectations.

Based on the clinically proven EQUIA system, EQUIA Forte offers a great alternative for a dental professional's daily routine.

More information is available by contacting GC UK Ltd on 01908 218999, emailing info@gcukltd.co.uk or visiting www.gceurope.com.

\section{Optical precision assured}

Look to Nuview for cutting-edge loupes from world-renowned manufacturer, Carl Zeiss.

The EyeMag Pro and EyeMag Smart loupes deliver superior image quality in peripheral zones and a greater depth of field for excellent depth orientation. These solutions also provide improved differentiation and a wide range of working distances, thereby facilitating professional workflows.

Achieve true visual clarity without compromising on comfort - or style for that matter, as the new sports frames from Carl
Zeiss combine enhanced viewing with a modern design.

More information is available by calling Nuview on 01453 872266, emailing info@ nuview-ltd.com, or visiting www.nuview.co.
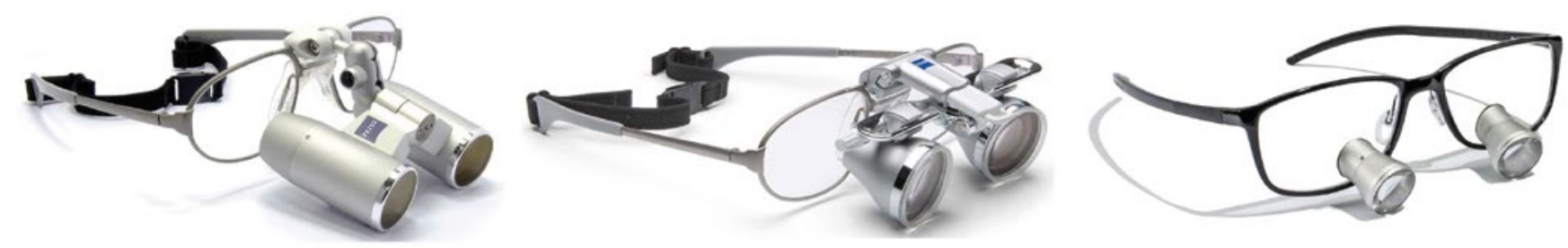

\section{Reach new heights}

Practitioners can enhance the mechanical performance and aesthetic outcome of implant treatment using TBR's Z1.

It features a biocompatible titanium body and unique zirconia collar - now available, not only at the $1.5 \mathrm{~mm}$ standard height, but also at a $2.5 \mathrm{~mm}$ height.

The $\mathrm{Z} 1$ ensures that no matter the clinical situation, practitioners can adapt treatment according to the thickness of the soft tissue and the depth at which they aim to place the implant.

This unique system also protects the crestal bone and the gingiva against periodontal pathogens that could otherwise compromise implant stability and the overall visual result.

More information on the $\mathrm{Z} 1$ implant is available by visiting https://www. tbr.dental/en/, emailing support@ denkauk.com or calling 08007076212 .

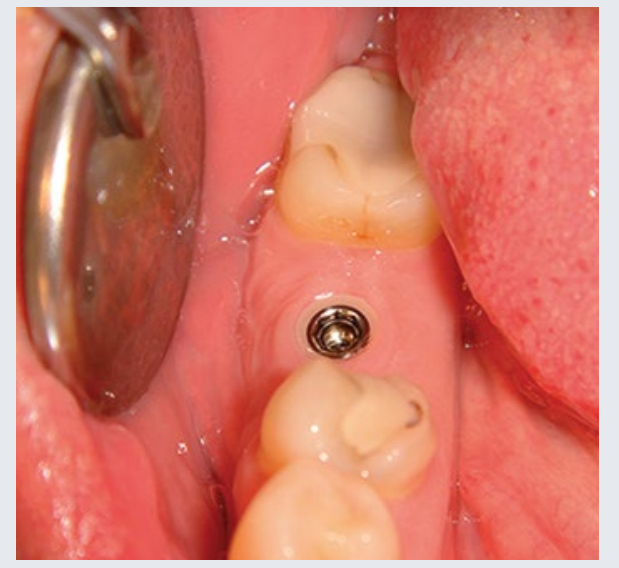

